\title{
Treatment with the Chk1 inhibitor Gö6976 enhances cisplatin cytotoxicity in SCLC cells
}

\author{
RUTH THOMPSON ${ }^{1,3}$, MARK MEUTH $^{1}$, PENELLA WOLL $^{2}$, YONG ZHU $^{1}$ and SARAH DANSON ${ }^{2}$ \\ ${ }^{1}$ Institute for Cancer Studies, Sheffield University Medical School, Beech Hill Road, Sheffield S10 2RX; \\ ${ }^{2}$ Academic unit of Clinical Oncology, Weston Park Hospital, Whitham Road, Sheffield S10 2SJ, UK
}

Received June 30, 2011; Accepted August 8, 2011

DOI: 10.3892/ijo.2011.1187

\begin{abstract}
Acquired chemoresistance is a major obstacle in successful treatment of small cell lung cancer (SCLC). DNA damage responses can potentially contribute to resistance by halting the cell cycle following exposure to therapeutic agents, thereby facilitating repair of drug-induced lesions and protecting tumour cells from death. The Chk1 protein kinase is a key regulator in this response. We analysed the status of cell cycle checkpoint proteins and the effects of the Chk1 inhibitor Gö6976 on cisplatin toxicity in SCLC cell lines. $\mathrm{IC}_{50} \mathrm{~s}$ for cisplatin were determined using the MTT assay in six SCLC cell lines. Effects on cell cycle distribution and apoptosis were determined by flow cytometry and caspase 3 activation in the presence or absence of the Chk1 inhibitor Gö6976. The activation of checkpoint proteins was determined by Western blotting. Cell lines were divided into chemosensitive and chemoresistant groups on the basis of our results. While checkpoint responses were detected in these cell lines through Western blotting, some of these responses were delayed or weaker than those seen in other cell types in response to DNA damage and replication stress. Gö6976 significantly $(\mathrm{p}<0.05)$ enhanced the levels of apoptosis seen in response to a clinically relevant dose of cisplatin $(<6 \mu \mathrm{M})$ and decreased drug-induced $\mathrm{G} 2$ arrest in chemosensitive cells. Our data suggest a role for Chk1 in chemoresistance of SCLC cells and a potential approach to improve initial response of SCLC to cisplatin therapy.
\end{abstract}

\section{Introduction}

Lung cancer is the leading cause of cancer-related death in the developed world in both sexes (1). Small cell lung cancer (SCLC) accounts for $\sim 20 \%$ of lung cancers. SCLC is distinguished from NSCLC (non-small cell lung cancer) by characteristic biological and pathological features and by its

Correspondence to: Dr Ruth Thompson, ${ }^{3}$ Present address: Rubin 662, One Medical Center Drive, Department of Pharmacology and Toxicology, Dartmouth Medical School, Lebanon NH 03756, USA E-mail: ruth.h.thompson@dartmouth.edu

Key words: small cell lung cancer, chemoresistance, checkpoint kinase 1, Gö6976, cell cycle, cisplatin initial chemosensitivity. Standard first line treatment of SCLC with platinum-based chemotherapy results in objective tumour responses in $\sim 80 \%$ of patients and symptomatic benefit in even more. Unfortunately, most patients soon relapse with chemoresistant disease and ultimately die of the disease (2). Treatment of relapsed or refractory SCLC is an ongoing problem for oncologists and patients and new approaches to overcome platinum chemoresistance are urgently required.

Cisplatin is widely used in the treatment of solid tumours. Its cytotoxic activity is based on its interaction with cellular DNA leading to the formation of adducts derived from intraor interstrand crosslinks (ICLs) (3). Such crosslinks result in delayed $S$ phase transit and ultimately G2 arrest $(4,5)$. It has been proposed that cisplatin-induced interstrand crosslinks are processed to double-strand breaks (DSBs) following an encounter with a replication fork (6). Radiation-induced DSBs induce ATM (Ataxia telangiectasia mutated) autophosphorylation which in turn leads to cell cycle arrest via activation of p53, Chk2 and, ultimately, Chk1. It has been shown that ATM is also induced in response to cisplatin treatment (7) but interestingly, this ATM phosphorylation is attenuated in nucleotide excision repair (NER) deficient cells (8). This suggests that the ICLs are initially recognised by the NER system which processes them to lesions that lead to DSBs, ATM-mediated cell cycle arrest, and DSB repair. This response may contribute to chemoresistance by enhancing repair of cisplatin-induced lesions in cancer cells.

Abrogating checkpoint pathways that trigger cell cycle arrest can induce apoptosis in cisplatin-resistant cells (9). 7-hydroxystaurosporine (UCN-01), a protein kinase antagonist, preferentially inhibits protein kinase $\mathrm{C}$ but also inhibits the serine/threonine kinase AKT, cyclin-dependent kinases (CDKs) and checkpoint kinase 1 (Chk1) $(10,11)$. UCN-01 has been shown to potentiate the toxicity of cisplatin by abrogation of $\mathrm{G} 2$ and $\mathrm{S}$ phase arrest $(12,13)$. In NSCLC cell lines, UCN-01 dramatically reduced the proportion of cells in cisplatininduced G2 arrest and increased the ability of cisplatin to induce apoptosis. This effect was only seen when the inhibitor was added $16 \mathrm{~h}$ after the cisplatin treatment and not when UCN-01 was added before cisplatin. This was thought to be because UCN-01 itself causes G1 arrest (14).

Despite the initial promise of UCN-01 in vitro, phase I clinical trials revealed a strong affinity to the human plasma protein $\alpha 1$ - acid glycoprotein resulting in a prolonged half-life 
and decreased bioavailability (15). Furthermore, UCN-01 acts as an inhibitor of many kinases that could result in adverse side-effects in patients. As a potential alternative, Gö6976 is an indolocarbazole which is similar in structure to UCN-01 but has lower toxicity and greater selectivity for inhibiting protein kinases than UCN-01 and is unaffected by the presence of human serum. Importantly it also abrogates S and G2 arrest via inhibition of the checkpoint kinase protein Chk1 (16).

While cellular responses to cisplatin have been widely studied in many types of cultured tumour cells, little is known of the response to SCLC cells to this agent despite its use as a first-line agent in therapies for these tumours, largely because of the difficulties in growing SCLC cells in vitro. The large floating aggregates these non-adherent cells form in culture hinder many in vitro techniques. The aim of this study was to characterize checkpoint responses in cultured SCLC cells and to determine whether these responses could be exploited to improve response to this agent. Here we show that there is a marked difference in the cell cycle response to cisplatin between the sensitive and resistant SCLC cell lines tested here and that inhibition of the DNA damage response protein Chk1 led to enhancement of cell death at clinically relevant doses of cisplatin, most notably in the primary, sensitive SCLC cell lines.

\section{Materials and methods}

Cell cultures. SCLC cell lines H69, H82, H345 and H711 were acquired from ATCC. The Lu165 cell line was a gift from Dr T. Terasaki (National Cancer Center, Tokyo Japan). The Glc19 cell line was a gift from The Groningen Lung Cancer Group (Groningen, The Netherlands). The cells were maintained in suspension cultures in RPMI medium supplemented with $10 \%$ foetal calf serum (FCS). Cells were incubated at $37^{\circ} \mathrm{C}, 5 \%$ $\mathrm{CO}_{2}$. Cisplatin (Sigma-Aldrich, Dorset, UK) was dissolved in water and Gö6976 (Sigma-Aldrich) was dissolved in DMSO (Sigma-Aldrich). Both were stored in the dark at $-20^{\circ} \mathrm{C}$. Cells were incubated for $1 \mathrm{~h}$ with Gö6976 prior to $48 \mathrm{~h}$ cisplatin treatment.

MTT assay. Cells were plated in 24-well plates (1 ml suspension/well) in RPMI (+10\% FCS) at a concentration of $5 \times 10^{4}$ cells $/ \mathrm{ml}$ and incubated for $4 \mathrm{~h}$ at $37^{\circ} \mathrm{C}$ prior to treatment (17). The cells were treated with cisplatin, each dose was plated in triplicate. Followed by the addition of $100 \mu \mathrm{l} /$ well thiazolyl blue tetrazolium bromide (MTT) solution $(5 \mathrm{mg} / \mathrm{ml}$; SigmaAldrich) the plates were incubated at $37^{\circ} \mathrm{C}$ for $\sim 30$ min or until sufficient purple coloration developed. The contents of each well were transferred to a 1-ml Eppendorf tube and centrifuged at $2000 \mathrm{x} \mathrm{g}$ for $5 \mathrm{~min}$. The supernatants were removed and cell pellets left in the tube. The cells were resuspended in $100 \mu 1$ DMSO by pipetting until all crystals had dissolved. The contents of each Eppendorf were transferred to one well of a 96-well plate which was read in a plate reader at a wavelength of $570 \mathrm{~nm}$ (ref. $690 \mathrm{~nm}$ ). The optical density of the untreated controls was taken as $100 \%$ cell viability and all subsequent readings were calculated as a percentage of the control.

Caspase 3 activation assay. To quantify levels of apoptosis, the active caspase 3 levels were ascertained using a Caspase 3 detection kit (Axxora, Nottingham, UK) (18). The cells were processed further to allow simultaneous analysis of the cell cycle by flow cytometry. Cells $\left(5 \times 10^{4} / \mathrm{ml}\right)$ were plated in 6 -well plates ( $3 \mathrm{ml}$ suspension/well) and treated with the stated dose of cisplatin for $48 \mathrm{~h}$. Following treatment, cells were incubated with the caspase-3 inhibitor DEVD-FMK conjugated to FITC $(1 \mu \mathrm{l} / \mathrm{ml})$ then resuspended in phosphate-buffered saline (PBS) containing $50 \mu \mathrm{g} / \mathrm{ml}$ propidium iodide (PI), $100 \mu \mathrm{g} / \mathrm{ml}$ RNase A and $0.1 \%$ Triton $\mathrm{X}-100$ and incubated at $-4^{\circ} \mathrm{C}$ in the dark for $60 \mathrm{~min}$. Analysis was carried out on a Beckton-Dickinson FACSCalibur cytometer using CellQuest Pro software.

Cell cycle analysis. Cell cycle analysis was performed using flow cytometric evaluation of DNA content. Following cisplatin treatment, cell suspensions were washed once in PBS, and resuspended in ice cold $70 \%$ ethanol. Cells were stored at $-20^{\circ} \mathrm{C}$ for at least $24 \mathrm{~h}$ to allow for perforation of the cell membrane. After fixing, the cells were washed in PBS, $5 \mu 1$ RNAse A was added to remove any RNA to which the PI could bind. PI solution ( $500 \mu \mathrm{l}$ of $5 \mathrm{mg} / \mathrm{ml}$ ) was added to dilute the RNase A to a final concentration of $100 \mu \mathrm{g} / \mathrm{ml}$. The cells were stored in the dark at $-4^{\circ} \mathrm{C}$ overnight before FACs analysis.

Western blotting. Cell lysates were prepared and fractionated on SDS-PAGE gels before being blotted onto nitrocellulose (Whatman, Scleicher and Schull, Dassel, Germany) as described previously (19). Protein bands were visualized using the ECL detection system (GE Healthcare, Little Chalfont, Buckinghamshire, UK) using antibodies recognizing ATM (GeneTex, Irvine, CA, USA), phospho-ATM (Ser 1981) (Epitomics, Burlingame, CA, USA), total Chk1, phospho-Chk1 (Ser 296), phospho-Chk1 (Ser 345), phospho-H2AX (Cell Signaling, Herts, UK), $\beta$-actin (Sigma-Aldrich) and RPA34 (Calbiochem, Nottingham, UK).

\section{Results}

Chemosensitivity of SCLC cell lines to cisplatin. Platinum drugs are the primary chemotherapeutic agents used to treat SCLC. The cisplatin levels required to induce $50 \%$ cell death $\left(\mathrm{IC}_{50}\right)$ after $48 \mathrm{~h}$ treatment were determined for each cell line using the MTT assay. Dose-response curves were constructed for each cell line and the resulting $\mathrm{IC}_{50}$ was calculated (Fig. $1 \mathrm{~A}$ and B). The two out of the six cell lines derived from primary tumours prior to treatment (H69 and H82), and the cell line derived from a secondary tumour pretreated with drugs besides cisplatin (Glc19) were all relatively sensitive to cisplatin with $\mathrm{IC}_{50} \mathrm{~s}$ of 4-12 $\mu \mathrm{M}$. In contrast, the three cell lines derived from secondary metastases of tumours pretreated with cisplatin (H345, H711 and Lu165) were considerably more chemoresistant with $\mathrm{IC}_{50} \mathrm{~s}$ of $40-100 \mu \mathrm{M}$ (Fig. 1B).

To assess whether decreased cell viability corresponded to increased levels of apoptosis, the levels of cleaved caspase 3 were measured. Caspase 3 cleavage is a marker of cells undergoing apoptosis. Fig. 1C shows that levels of cleaved caspase 3 corresponded to the loss of viability determined by the MTT assays in the sensitive cells. The data are insufficient to make the same conclusion for the resistant cells but there was a small but significant ( $\mathrm{p}=0.0103$, paired $\mathrm{t}$-test) increase in the level of caspase 3 activation in the resistant cells up to the cisplatin concentration of $25 \mu \mathrm{M}$ (Fig. 1C). 
A

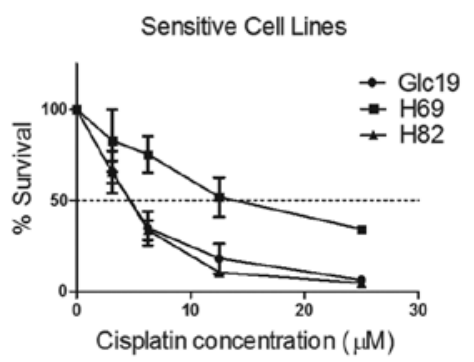

C

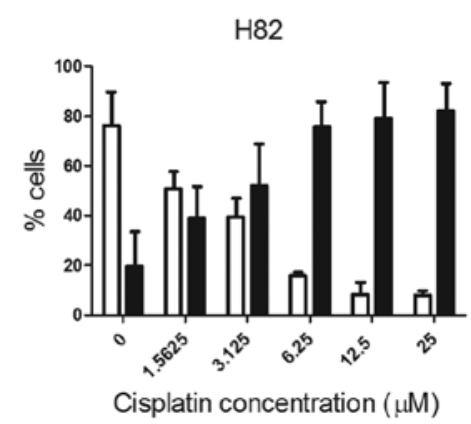

B

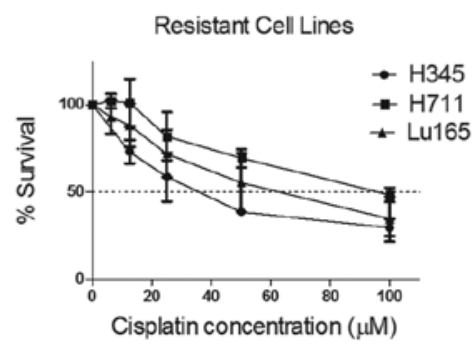

\begin{tabular}{ll}
\hline Cell Line & $\mathrm{IC}_{50}$ ( $\mu \mathrm{M}$ cisplatin) \\
\hline Glc19 & $4.5+/-0.97$ \\
$\mathrm{H} 69$ & $11.5+/-1.98$ \\
$\mathrm{H} 82$ & $6.6+/-2.67$ \\
$\mathrm{H} 345$ & $41.5+/-2.83$ \\
H711 & $97.1+/-2.97$ \\
Lu165 & $65.5+/-5.66$
\end{tabular}

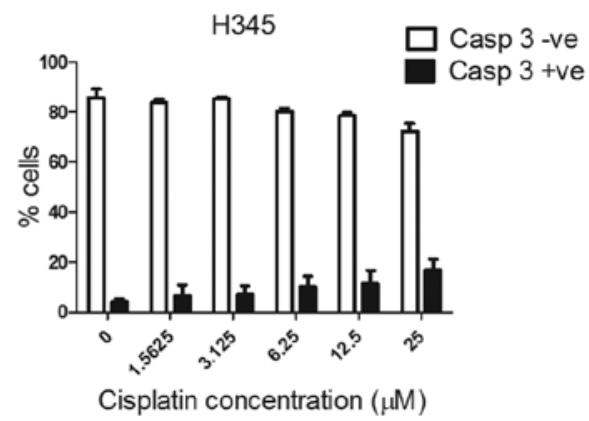

Figure 1. Dose response of SCLC cell lines to cisplatin. Cells were treated with different doses of cisplatin for 48 h. (A) Comparison of IC ${ }_{50}$ curves for the sensitive and resistant cell lines. Viability of sensitive (H82) and resistant (H345) SCLC cell lines in cisplatin was determined by the MTT assay data. Results performed in triplicate; data shown as mean $\pm \mathrm{SD}$. (B) $\mathrm{IC}_{50}$ doses for cisplatin in each of the six cell lines calculated from the MTT assay. Data shown as mean $\pm \mathrm{SD} n=3$. (C) Caspase 3 activation was analysed by flow cytometry at $48 \mathrm{~h}$ post treatment with cisplatin. Data shown as mean \pm SD $n=3$. Caspase - ve, cells not expressing the active form of caspase 3; caspase +ve, cells expressing the cleaved, active form.

Cell cycle response to cisplatin. To determine the effect of cisplatin on cell cycle distribution of the SCLC cell lines, the cell cycle profiles were visualised using fluorescence-activated cell sorting (FACS) following treatment with the clinically achievable doses of 1 and $6 \mu \mathrm{M}$ cisplatin for $48 \mathrm{~h}$. There was a marked difference in the cell cycle response of the two groups. The three cisplatin-sensitive cell lines exhibited accumulation in G2 whereas the three more chemoresistant cell lines demonstrated $\mathrm{S}$ phase arrest. One cell line from each group is shown (Fig. 2A). Statistical analysis of data from five independent experiments showed that the changes in cell cycle profiles were significant $(\mathrm{p}<0.01$, Two-Way ANOVA). All cell lines also showed a visible increase in cells having a subG1 DNA content following cisplatin treatment (Fig. 2B). Treatment with the mitotic inhibitor nocodazole revealed that the $\mathrm{H} 345$ cells did not pass through G2/M before arresting in S while the H82 cells arrested in $\mathrm{G} 2$ prior to mitosis (data not shown).

Activation of checkpoint proteins in SCLC cells in response to cisplatin. To determine whether the differences in cell cycle response to clinically achievable doses of cisplatin were the result of defects in the DNA damage checkpoints, Western blot analysis was performed to determine the presence of important checkpoint proteins and the phosphorylation of these proteins following cisplatin treatment. This analysis revealed that Chk1 was weakly phosphorylated in response to drug treatment at both the ATM/ATR-mediated phosphorylation site (Ser 345) and the autophosphorylation site (Ser 296) (20) in response to the clinically achievable dose of $5 \mu \mathrm{M}$ cisplatin.
ATM phosphorylation also occurred in both subsets of cells. Interestingly, RPA hyperphosphorylation [that in some reports is associated with cells committed to death (21)] was only seen in the sensitive cells following cisplatin treatment. Western blot analysis of the phosphorylated forms of these proteins in cell extracts prepared from cells treated for 1,2 or $24 \mathrm{~h}$ were performed with one sensitive and one resistant cell line to analyse the rapidity of these phosphorylation events. Analysis of Chk1 phosphorylation in $\mathrm{H} 82$ and $\mathrm{H} 345$ cells at these earlier times post treatment revealed that Chk1 phosphorylation was not detectable until $24 \mathrm{~h}$ following treatment in either cell line. Phosphorylation of ATM and H2AX was only detected in the resistant $\mathrm{H} 345$ cell line after $24 \mathrm{~h}$ and this response was weaker than in the sensitive H82 cell line (Fig. 2D). Thus, while checkpoint responses can be detected in SCLC cells, some of these responses are delayed or weaker than those seen in other cell types in response to DNA damage and replication fork stress (22).

Effects of Gö6976 on apoptosis and cell cycle distribution in SCLC cell lines following cisplatin treatment. Recent work by several groups has shown that Chk1 plays a key role in protecting $\mathrm{S}$ phase arrested cells from apoptosis following treatment with replication inhibitors (reviewed in ref. 23). To determine whether the response of the SCLC cells to cisplatin could be enhanced by inhibiting Chk1, cells were pre-incubated for $1 \mathrm{~h}$ with DMSO or $100 \mathrm{nM}$ of the Chk1 inhibitor Gö6976 prior to $48 \mathrm{~h}$ cisplatin treatment. MTT assays and Western blotting were used to determine the ideal Gö6976 concentration 

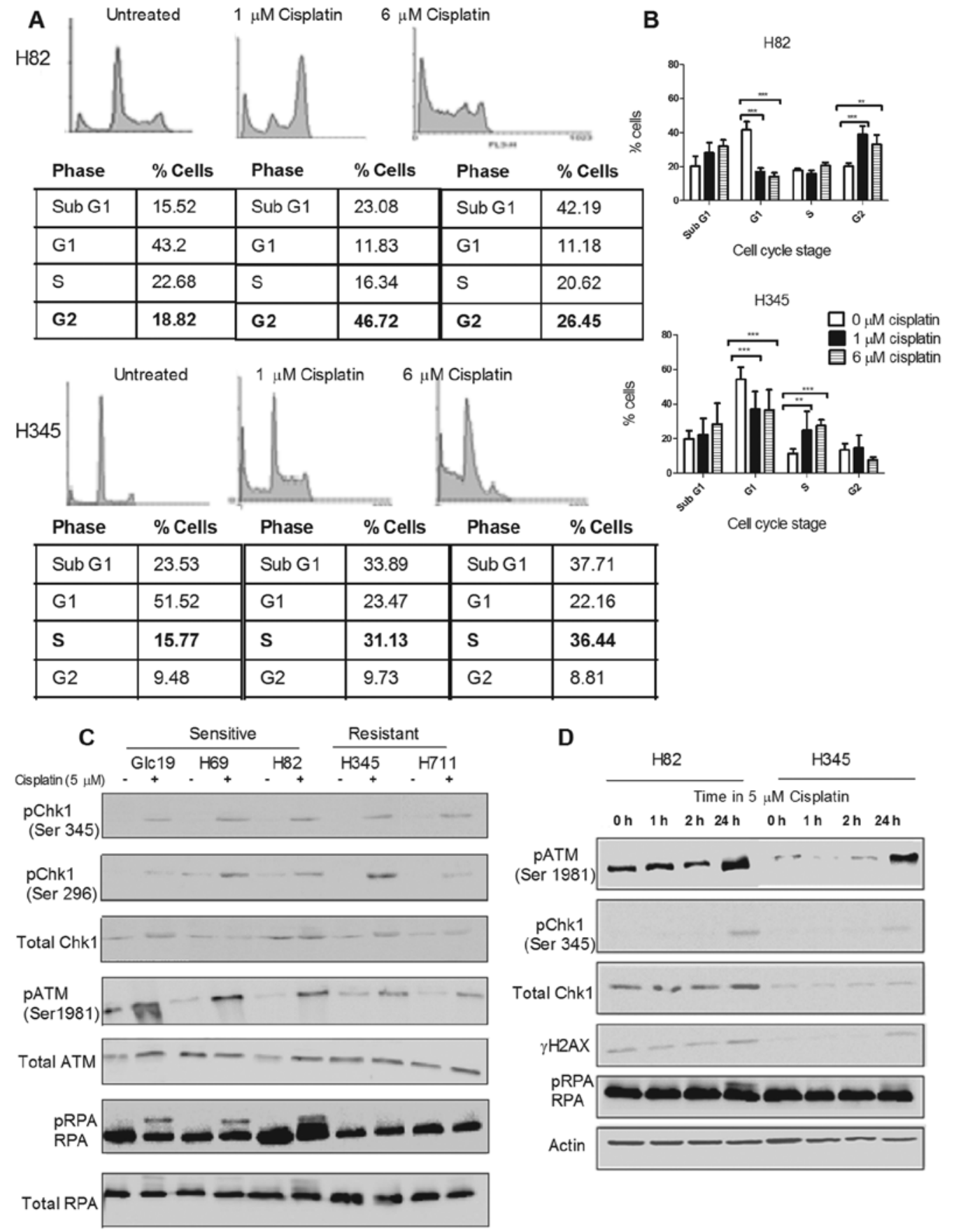

Figure 2. Cell cycle analysis of sensitive and resistant SCLC cell lines following cisplatin treatment. (A) Representative cell cycle profiles determined by PI staining and flow cytometry of cells exposed to cisplatin for $48 \mathrm{~h}$. (B) Collective data of five independent cell cycle profiles. Results analysed using Two-Way ANOVA with Bonferroni post test. "Significance of drug treatments against no cisplatin control; ${ }^{* *} \mathrm{p}<0.01,{ }^{* * *} \mathrm{p}<0.001$, mean \pm SD. (C and D) Western blot analysis of checkpoint proteins involved in the $\mathrm{S}$ and G2 checkpoints in cells treated with cisplatin for $48 \mathrm{~h}$ (C) or shorter time points (1-24 h) (D) Unfortunately loading controls for each individual protein could not be performed in Fig. 2D due to low protein yield.

to inhibit Chk1 but not induce high levels of death in both sensitive and resistant cells (data not shown). To determine the efficacy of Gö6976 in inhibiting Chk1, Western blottings for the Chk1 autophosphorylation site Ser 296 were carried out following treatment with cisplatin, Gö6976 and combination treatment. This revealed that Gö6976 inhibited cisplatin-induced Chk1 autophosphorylation (one cell line from each group is presented in Fig. 3A). MTT analysis revealed that Gö6976 only decreased the cisplatin $\mathrm{IC}_{50}$ in the sensitive cells (Fig. 3B). To analyse whether Gö6976 increased levels of death at clini- cally relevant doses of cisplatin, a more relevant measure with regards to treatment, the percentage of cells with subG1 DNA content was analysed. SubG1 is indicative of cell debris which indicates cell death. The subG1 proportion of cells was significantly increased following combination treatment compared to treatment with cisplatin alone $(\mathrm{Glc19} \mathrm{p}=0.01, \mathrm{H} 69 \mathrm{p}=0.035$, H82 $\mathrm{p}=0.001$, paired t-test) (Fig. 3C). Among the resistant cell lines, $\mathrm{H} 345$ showed a significant increase in the fraction of cells with subG1 DNA content after combination treatment $(\mathrm{p}=0.019$, paired t-test). While the Lu165 cells also showed some increase, 
A

$\mathrm{H} 82$

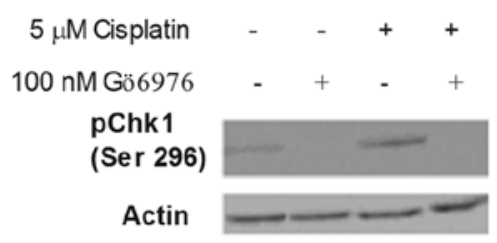

$\mathrm{H} 345$

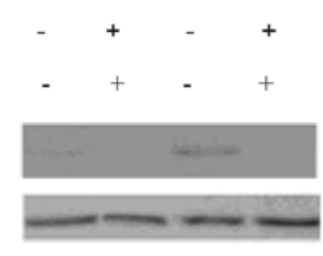

B

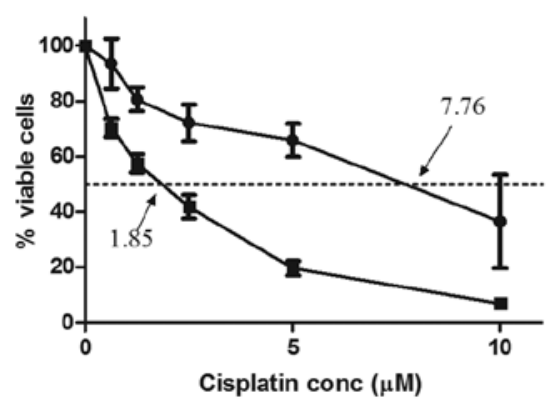

H345

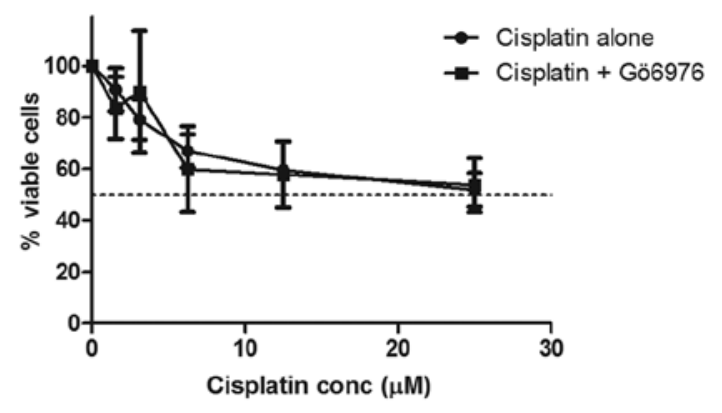

C

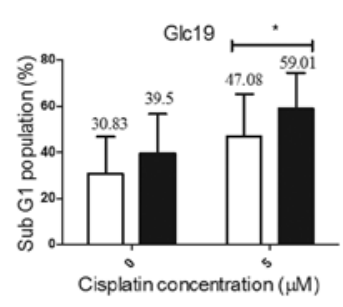

H345

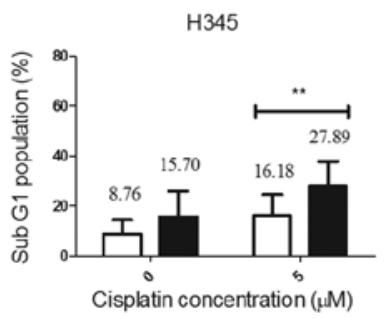

H69

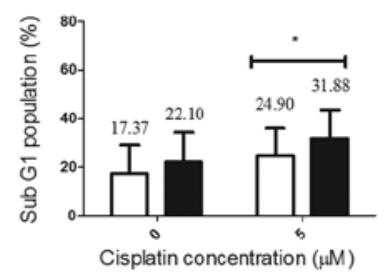

Cisplatin concentration $(\mu \mathrm{M})$

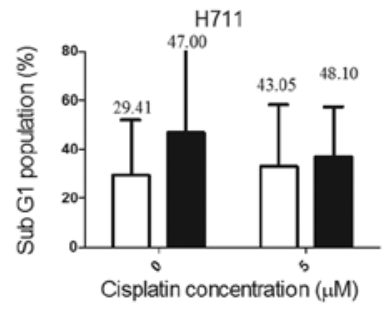

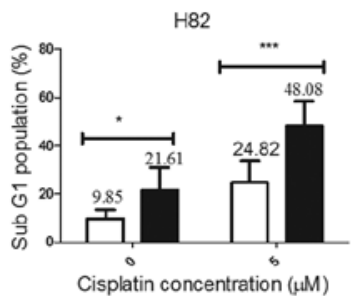

口 DMSO

Lu165

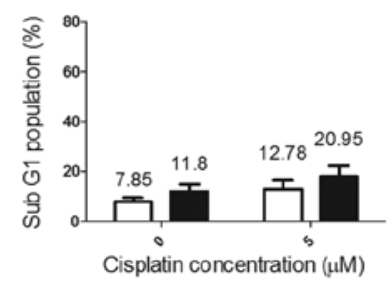

Figure 3. Gö6976 inhibits Chk1 and potentiates cisplatin cytotoxicity. (A) Western blot showing the Chk1 autophosphorylation at Ser 296 following cisplatin treatment and combination treatment with $100 \mathrm{nM}$ Gö6976 and $5 \mu \mathrm{M}$ cisplatin. (B) $\mathrm{IC}_{50}$ curves for cisplatin in one sensitive and one resistant cell line with and without $100 \mathrm{nM}$ Gö6976 calculated from the MTT assay. Mean \pm SD n=3. (C) Percentage of cells in the SubG1 population following cisplatin treatment in the presence or absence of $100 \mathrm{nM}$ Gö6976. Mean \pm SD n=8. Mean is presented above each data set. Results were analysed using paired t-test. *Significance of combination drug treatments against cisplatin alone; ${ }^{*} \mathrm{p}<0.05,{ }^{* *} \mathrm{p}<0.01,{ }^{* * *} \mathrm{p}<0.001$.

it did not reach significance. The H711 cells showed little or no effect. Similar results were obtained when cleaved caspase 3 was measured as an indicator of apoptosis (data not shown).

Gö6976 has been reported to enhance the cytotoxicity of DNA damaging agents by abrogating cell cycle arrest. To test this hypothesis, cell cycle profiles of cells treated with cisplatin alone and cisplatin with Gö6976 were examined. Cell cycle profiles of cells treated with $1 \mu \mathrm{M}$ cisplatin are shown here as at 6 $\mu \mathrm{M}$ the higher levels of subG1 population in the H82 cells make the profiles difficult to compare. In the chemosensitive H82 cells, there was a $60 \%$ reduction in the proportion of $\mathrm{G} 2$ cells following combination treatment $(\mathrm{p}<0.001$, Two-Way ANOVA) and there was a corresponding increase in the level of cells with subG1 DNA content $(\mathrm{p}<0.001$, Two-Way ANOVA). In some cases there was a reduction in the percentage of the resistant $\mathrm{H} 345$ cells in $\mathrm{S}$ phase following combination treatment but this was not consistent and did not reach significance although there was a significant increase in the level of cells with a subG1 DNA content (Fig. 4).

Effects of the drug combination on apoptosis and cell cycle distribution were not altered by the order of administration. Previous work has indicated the necessity for UCN-01 to follow cisplatin treatment in order to potentiate toxicity (14). In 


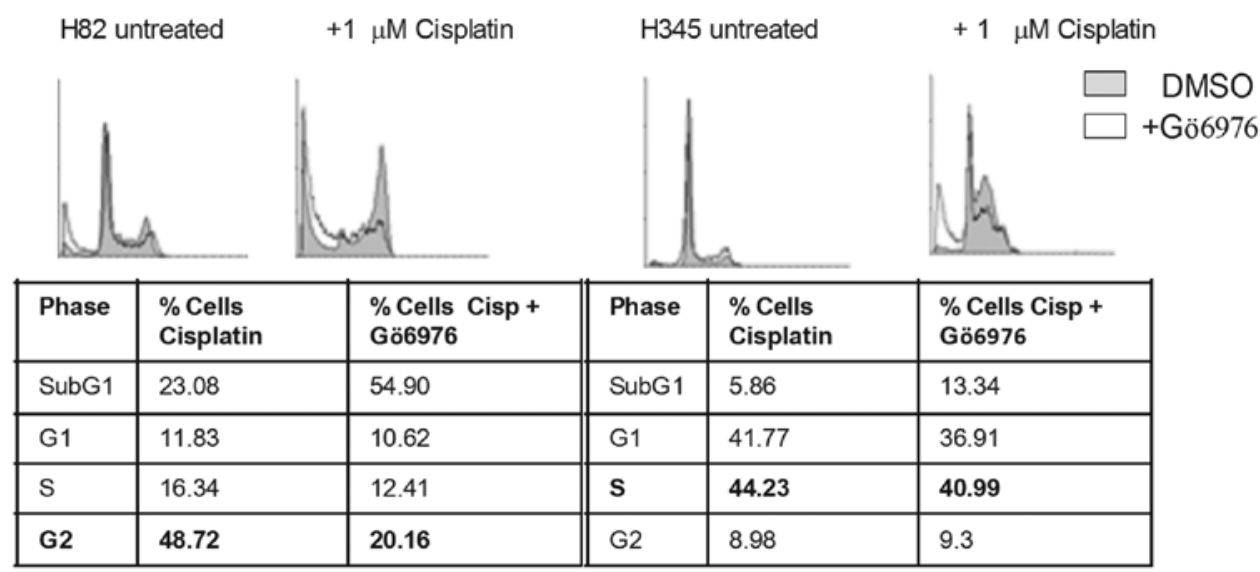

B

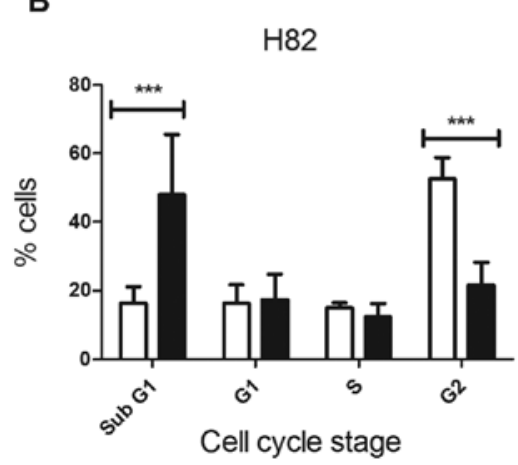

H345

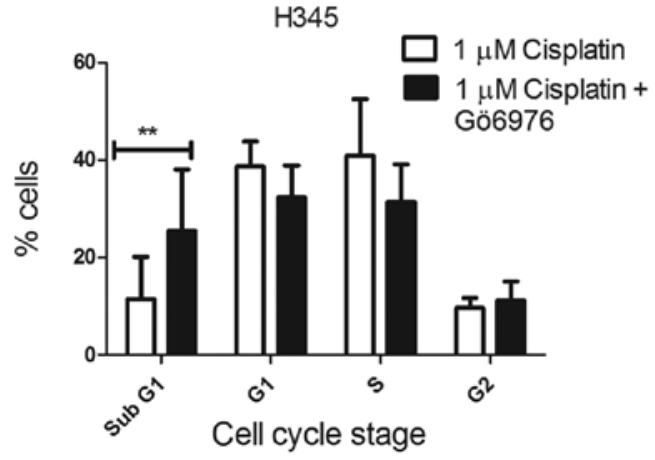

Figure 4. Effects of 100 nM Gö6976 on cisplatin-induced cell cycle arrest in SCLC cell lines. (A) Representative cell cycle profiles of a chemosensitive and a chemoresistant cell line treated with cisplatin alone and $1 \mu \mathrm{M}$ cisplatin $+100 \mathrm{nM}$ Gö6976. (B) Collective data of four independent experiments. Results analysed using a Two-Way ANOVA with Bonferroni post test. "Significance of combination treatment against cisplatin alone. ${ }^{*} \mathrm{p}<0.05,{ }^{* *} \mathrm{p}<0.01,{ }^{* * *} \mathrm{p}<0.001$. Mean \pm SD.

contrast, Gö6976 has been administered $1 \mathrm{~h}$ prior to cisplatin treatment (24) or $24 \mathrm{~h}$ following cisplatin treatment (16). To determine whether the sequence of Gö6976 administration affected cisplatin-induced apoptosis and cell cycle arrest, the agent was added either $1 \mathrm{~h}$ before or $24 \mathrm{~h}$ after cisplatin treatment of sensitive or resistant SCLC cells. There was no significant difference in cell cycle distribution or the level of cells with subG1 DNA content in either chemosensitive or chemoresistant cells (Fig. 5A and B).

Effect of cisplatin and Gö6976 on RPA34 hyper-phosphorylation and $\gamma H 2 A X$ formation in SCLC cell lines. Replication protein A (RPA) binds to single-strand DNA (ssDNA) formed during the disruption of DNA replication and is involved in DNA replication, repair and recombination. Once bound to single-strand DNA, it recruits the ATRIP/ATR complex which acts to initiate the cell cycle arrest checkpoint (25). Previous work in our group has shown a dramatic increase in RPA 34 hyper-phosphorylation in Chk1-depleted cells treated with replication inhibitors followed by enhanced levels of $\gamma \mathrm{H} 2 \mathrm{AX}$ $(21,26)$. To assess the RPA hyper-phosphorylation and $\gamma \mathrm{H} 2 \mathrm{AX}$ levels in the chemosensitive and chemoresistant cell lines used here, protein was extracted from cells $48 \mathrm{~h}$ after treatment with $5 \mu \mathrm{M}$ cisplatin, $100 \mathrm{nM}$ Gö6976, or both in combination (with
Gö6976 added $1 \mathrm{~h}$ before cisplatin). The RPA and $\gamma \mathrm{H} 2 \mathrm{AX}$ levels were analysed by Western blot analysis (Fig. 6). Hyperphosphorylation slows the mobility of RPA on a polyacrylamide gel resulting in a band-shift of the hyper-phosphorylated protein. Sensitive H82 cells showed RPA hyperphosphorylation following treatment with cisplatin alone which was enhanced by Gö6976 combination. Cells treated with Gö6976 alone showed $\gamma \mathrm{H} 2 \mathrm{AX}$ and this was further enhanced by combination treatment with cisplatin. The resistant cells showed a much weaker response for both $\gamma \mathrm{H} 2 \mathrm{AX}$ and RPA.

\section{Discussion}

The treatment of SCLC presents major challenges. Strategies to overcome drug resistance are needed to improve on current results obtained in clinical practice. The six cell lines studied were characterised into two groups based on their sensitivity to the cancer chemotherapy agent cisplatin. The mean peak plasma concentration attained in clinical use of cisplatin is $2 \mu \mathrm{g} / \mathrm{ml}$ which is equivalent to $6.66 \mu \mathrm{M}$ (27). The chemosensitive group exhibited decreased cell viability and increased levels of the apoptosis executioner protein, caspase 3 following $48 \mathrm{~h}$ of treatment with relatively low doses of cisplatin $\left(\mathrm{IC}_{50}\right.$ 4-12 $\mu \mathrm{M})$. The chemoresistant group required much higher 
A
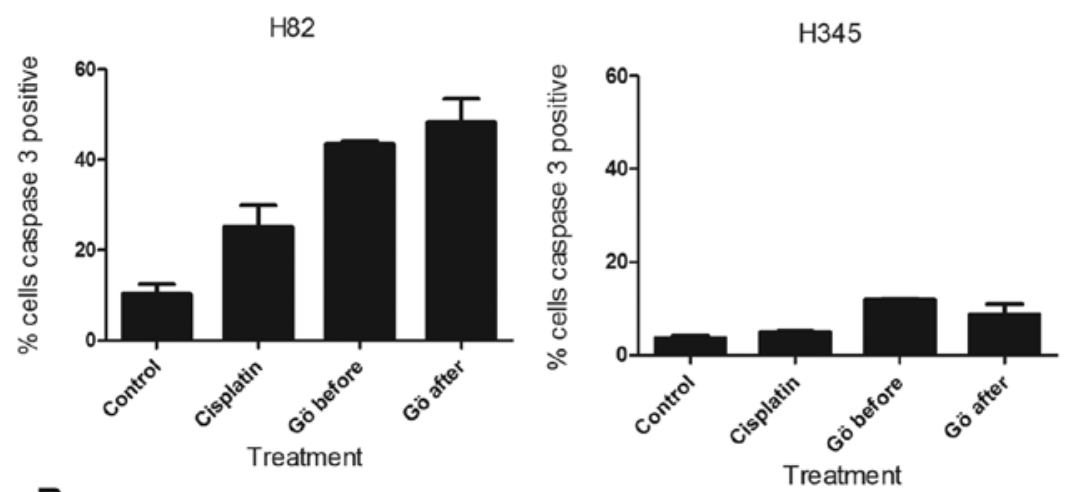

B
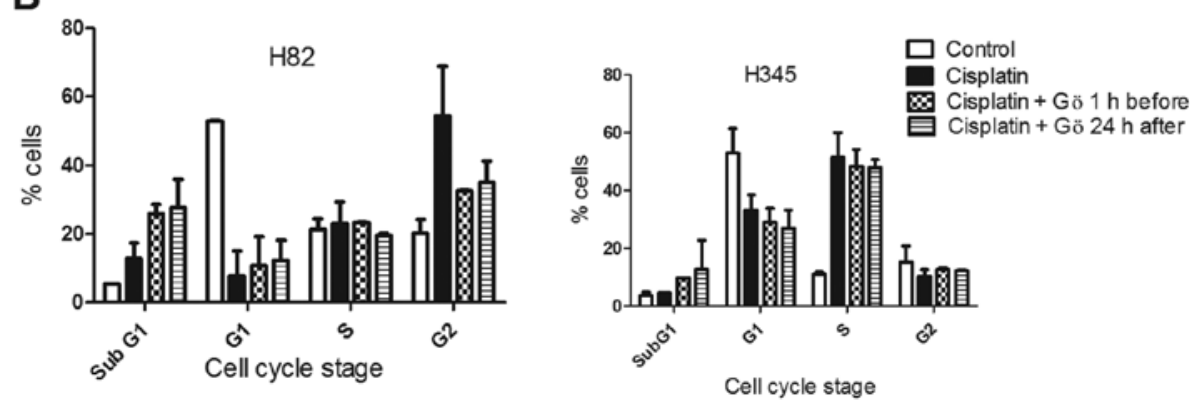

Figure 5. Effect of time of Gö6976 treatment on cell cycle arrest and the percentage of sensitive H82 and resistant H345 cells showing active caspase 3. (A) Expression of active caspase 3 in H82 and H345 cells following treatment. (B) Cell cycle distributions in H82 and H345 cells. In both cases, cells were treated for $48 \mathrm{~h}$ with $5 \mu \mathrm{M}$ cisplatin. Gö6976 $(100 \mathrm{nM})$ was added either $1 \mathrm{~h}$ before or $24 \mathrm{~h}$ after cisplatin.
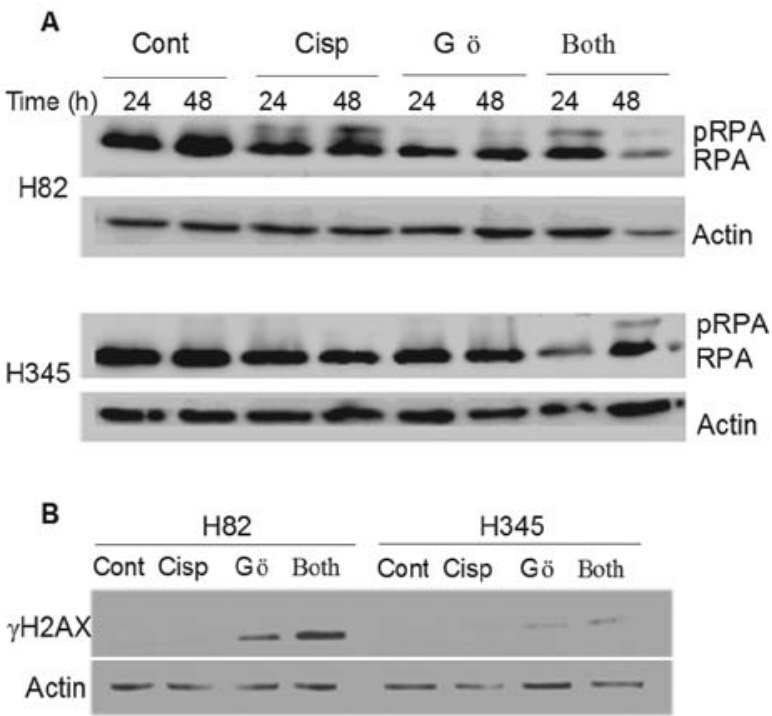

Figure 6. Phosphorylation of H2AX and RPA following cisplatin and Gö6976 treatment. Cells were treated for $48 \mathrm{~h}$ following $1 \mathrm{~h}$ pre-treatment with either DMSO or Gö6976. (A) RPA and hyper-phosphorylated RPA in H82 and H345 cells treated with cisplatin and Gö6976 as single agents or in combination. Cont, untreated control; Cisp, $5 \mu \mathrm{M}$ cisplatin; Gö, 100 nM Gö6976; Both, $5 \mu \mathrm{M}$ cisplatin $+100 \mathrm{nM}$ Gö6976. (B) $\gamma \mathrm{H} 2 \mathrm{AX}$ in $\mathrm{H} 82$ and $\mathrm{H} 345$ cells treated with cisplatin and Gö6976 as single agents or in combination. Cont, untreated control; Cisp, $5 \mu \mathrm{M}$ cisplatin; Gö, $100 \mathrm{nM}$ Gö6976; Both, $5 \mu \mathrm{M}$ cisplatin + 100 nM Gö6976.

cisplatin doses $\left(\mathrm{IC}_{50} 40-100 \mu \mathrm{M}\right)$ to achieve the same levels of cell death after $48 \mathrm{~h}$ treatment.
The chemosensitivity to cisplatin of the SCLC cell lines was determined using MTT and caspase 3 activation assays. These results corresponded well, with around $50 \%$ of cells expressing the cleaved form of caspase 3 at the $\mathrm{IC}_{50}$ dose determined by the MTT assay indicating that the reduction in cell number demonstrated in the MTT assay was due to apoptosis.

The differential cell cycle arrest between the two groups was interesting especially as previous studies in other human cancer cells suggest that cisplatin induces delayed $\mathrm{S}$ phase transit and ultimately G2 arrest $(4,27)$. S phase arrest as seen in the chemoresistant cells in this study has only been documented in hamster cells and human cell lines modified to overexpress various repair proteins $(13,28)$. There is less $\gamma \mathrm{H} 2 \mathrm{AX}$ and RPA hyperphosphorylation in the resistant $\mathrm{H} 345$ cells following treatment than in the sensitive H82 cells. This could be indicative of low levels of cisplatin uptake into the cells or high incidence of drug efflux. However, the fact that cisplatin induces a marked $\mathrm{S}$ phase arrest in the resistant cells indicates that the drug is entering the cell and causing damage therefore it is more likely that the mechanism of resistance is due to rapid repair of cisplatin-induced lesions in the resistant cells. We therefore speculate that the aberrant $S$ phase arrest in resistant cells may contribute to cisplatin resistance. Chk1 phosphorylation was weak and delayed relative to responses previously demonstrated by many groups in other cancer cell lines in response to damaging agents $(22,29)$. The presence of hyper-phosphorylated RPA in sensitive cells indicates evidence of persistent ssDNA after cisplatin treatment. This is further enhanced by combination treatment with Gö6976.

Previous work has demonstrated that the PKC/Chk1 inhibitor UCN-01 enhances cisplatin toxicity and abrogates cisplatin- 
induced S phase (13) and G2 arrest (30) in various cells, both tumour and non-tumour. This has been demonstrated in NSCLC cell lines but not in SCLC cells (14). Unfortunately the use of $\mathrm{UCN}-01$ in patients is not possible as it has a much increased half-life in human serum due to an unfavourable association with human $\alpha$-acid glycoprotein (15). It also interferes with non-checkpoint kinases thus disrupting other pathways (31). Although Gö6976 is similar to UCN-01 in structure, it is less toxic (having a 20 -fold higher $\mathrm{IC}_{50}$ in MDA-MB-231 cells than UCN-01) and does not interact with human $\alpha$-acid glycoprotein (16). Like UCN-01, Gö6976 was originally identified as a PKC inhibitor and inhibits the $\mathrm{Ca}^{+}$-dependent $\alpha$ and $\beta$ subtypes of PKC (32) but both UCN-01 and Gö6976 are extremely effective at abrogating DNA damage-induced S and G2 arrest $(12,13,33,34)$. Following analysis of checkpoint proteins it has been concluded that this is due to the inhibition of Chk1 function $(11,16,35)$. It is however important to note that Gö6976 is not specific to PKC and Chk1. It has also been shown to block neotrophin-induced signalling and autophosphorylation of the specific tyrosine kinase receptors TrkA and TrkB (36). It has also been reported that Gö6976 is a direct inhibitor of both the Janus-activated kinase JAK2 and the FMS-like tyrosine kinase 3 (FLT3) (37). It should be noted, however that the involvement of these signalling pathways in the response to replication stress has not been documented. In addition to the known direct targets, Gö6976 will also affect proteins downstream of those mentioned above.

The cell cycle-dependent potentiation of cisplatin by UCN-01 in NSCLC cell lines was only seen when UCN-01 was added $16 \mathrm{~h}$ after cisplatin (14). This was proposed to be due to G1 arrest induced by UCN-01 when used alone. Gö6976 has no obvious effects on the cell cycle profiles of SCLC cell lines used here (except on the proportion of SubG1 cells) and experiments comparing the addition of Gö6976 before and after cisplatin indicate that the order of administration makes no difference to the effects (Fig. 5).

Here, Gö6976 abrogated cisplatin-induced cell cycle arrest in chemosensitive SCLC cells and potentiated cisplatininduced apoptosis in both chemosensitive and chemoresistant cell lines at cisplatin levels relevant to clinical practice. This is demonstrated by data obtained from both subG1 and caspase 3 activation analysis. The effect of Gö6976 is greater in the sensitive cells. This could be clinically valuable as further enhancing apoptosis in the primary tumours could reduce the risk of relapse or delay it by reducing the level of surviving cells. All the SCLC cell lines used here are p53 deficient. It has been suggested that in the absence of Chk1, p53-deficient tumour cells may die via a caspase 2-mediated pathway following exposure to ionizing radiation (38) although replication inhibitors trigger a caspase 3-dependent pathway (39). Western blot analysis failed to reveal activation of caspase 2 in these cells in the presence or absence of Gö6976 following cisplatin treatment in the SCLC lines tested (data not presented).

The cisplatin-induced G2 peak seen in the chemosensitive cells was significantly diminished following treatment with the Chk1 inhibitor, consistent with the previously established role of Chk1 in the G2 arrest (40). The cisplatin-induced S phase arrest in chemoresistant cells was affected to a lesser extent suggesting that another pathway is involved in the maintenance of $\mathrm{S}$ phase arrest. The discovery of a class of human interstrand crosslink-hypersensitive mutants carrying mutations in one of the Fanconi anaemia genes (41) led to speculation that there is an ATR-dependent but Chk1-independent pathway that works in tandem with the ATR-Chk1 pathway in maintaining the $\mathrm{S}$ phase checkpoint in response to interstrand crosslinks (42). Experiments involving single and combination treatments with Chk1 and FANCD2 siRNA revealed that cells with interference of one or the other showed a partial decrease in number of cells in $\mathrm{S}$ phase but cells with concomitant interference of both proteins exhibited a complete loss of $S$ phase checkpoint activation (42). This could explain why Gö6976 has been reported to abrogate $\mathrm{S}$ phase arrest induced by other DNA-damaging drugs but does not abrogate cisplatin-induced $\mathrm{S}$ phase arrest here.

This study shows that Gö6976 decreased the cisplatin $\mathrm{IC}_{50}$ for sensitive cells and enhanced cisplatin cytotoxicity in several SCLC cell lines at the clinically achievable dose of $6 \mu \mathrm{M}$ cisplatin. This suggests that Chk1 inhibitors could be used to enhance the cytotoxic effects of cisplatin in primary sensitive SCLC tumours but more work is required to elucidate the mechanisms of chemoresistance. Notably three new Chk1 inhibitors are in clinical development (43) and the higher specificity of these inhibitors could further improve this response. Future work should focus on investigating inhibitors such as these in SCLC in combination with standard treatment of cisplatin with etoposide.

\section{Acknowledgements}

The authors thank Susan Newton for her assistance with the flow cytometry and Anil Ganesh for his expert technical assistance. This work was funded by Yorkshire Cancer Research (MM) and Weston Park Cancer Appeal (RHT, SD, YMZ and PW). The funding bodies had no role in the study design, or in the collection, analysis or interpretation of data, neither any role in the preparation of the manuscript or its submission for publication.

\section{References}

1. Jemal A, Siegel R, Ward E, et al: Cancer Statistics, 2008. CA Cancer J Clin 58: 71-96, 2008.

2. Eckert F and Muller AC: SCLC extensive disease-treatment guidance by extent or/and biology of response? Radiat Oncol 3: $33,2008$.

3. Fichtinger-Schepman AM, van der Veer JL, den Hartog JH, Lohman PH and Reedijk J: Adducts of the antitumor drug cis-diamminedichloroplatinum (II) with DNA: formation, identification, and quantitation. Biochemistry 24: 707-713, 1985.

4. Chu G: Cellular responses to cisplatin. The roles of DNA-binding proteins and DNA repair. J Biol Chem 269: 787-790, 1994.

5. Lambert S, Mason SJ, Barber LJ, et al: Schizosaccharomyces pombe checkpoint response to DNA interstrand cross-links. Mol Cell Biol 23: 4728-4737, 2003.

6. Niedernhofer LJ, Odijk H, Budzowska M, et al: The structurespecific endonuclease Ercc1-Xpf is required to resolve DNA interstrand cross-link-induced double-strand breaks. Mol Cell Biol 24: 5776-5787, 2004

7. Wang J, Pabla N, Wang CY, Wang W, Schoenlein PV and Dong Z: Caspase-mediated cleavage of ATM during cisplatin-induced tubular cell apoptosis: inactivation of its kinase activity toward p53. Am J Physiol Renal Physiol 291: F1300-F1307, 2006.

8. Colton SL, Xu XS, Wang YA and Wang G: The involvement of ataxia-telangiectasia mutated protein activation in nucleotide excision repair-facilitated cell survival with cisplatin treatment. J Biol Chem 281: 27117-27125, 2006. 
9. Shinomiya N, Takemura T, Iwamoto K and Rokutanda M: Caffeine induces S-phase apoptosis in cis-diamminedichloroplatinum-treated cells, whereas cis-diamminedichloroplatinum induces a block in G2/M. Cytometry 27: 365-373, 1997.

10. Takahashi I, Kobayashi E, Asano K, Yoshida M and Nakano H: UCN-01, a selective inhibitor of protein kinase C from streptomyces. J Antibiot (Tokyo) 40: 1782-1784, 1987.

11. Busby EC, Leistritz DF, Abraham RT, Karnitz LM and Sarkaria JN: The radiosensitizing agent 7-hydroxystaurosporine (UCN-01) inhibits the DNA damage checkpoint kinase hChk1. Cancer Res 60: 2108-2112, 2000.

12. Wang Q, Fan S, Eastman A, Worland PJ, Sausville EA and O'Connor PM: UCN-01: a potent abrogator of G2 checkpoint function in cancer cells with disrupted p53. J Natl Cancer Inst 88: 956-965, 1996.

13. Bunch RT and Eastman A: 7-Hydroxystaurosporine (UCN-01) causes redistribution of proliferating cell nuclear antigen and abrogates cisplatin-induced S-phase arrest in Chinese hamster ovary cells. Cell Growth Differ 8: 779-788, 1997.

14. Mack PC, Gandara DR, Lau AH, Lara PN Jr, Edelman MJ and Gumerlock PH: Cell cycle-dependent potentiation of cisplatin by UCN-01 in non-small-cell lung carcinoma. Cancer Chemother Pharmacol 51: 337-348, 2003.

15. Fuse E, Tanii H, Kurata N, et al: Unpredicted clinical pharmacology of UCN-01 caused by specific binding to human alpha1-acid glycoprotein. Cancer Res 58: 3248-3253, 1998.

16. Kohn EA, Yoo CJ and Eastman A: The protein kinase C inhibitor Go6976 is a potent inhibitor of DNA damage-induced S and G2 cell cycle checkpoints. Cancer Res 63: 31-35, 2003.

17. Carmichael J, Mitchell JB, DeGraff WG, et al: Chemosensitivity testing of human lung cancer cell lines using the MTT assay. Br J Cancer 57: 540-547, 1988

18. Li CH, Tzeng SL, Cheng YW and Kang JJ: Chloramphenicolinduced mitochondrial stress increases p21 expression and prevents cell apoptosis through a p21-dependent pathway. J Biol Chem 280: 26193-26199, 2005.

19. Bolderson E, Scorah J, Helleday T, Smythe C and Meuth M: ATM is required for the cellular response to thymidine induced replication fork stress. Hum Mol Genet 13: 2937-2945, 2004

20. Clarke CA and Clarke PR: DNA-dependent phosphorylation of Chk1 and Claspin in a human cell-free system. Biochem J 388: 705-712, 2005 .

21. Rodriguez R, Gagou ME and Meuth M: Apoptosis induced by replication inhibitors in Chk1-depleted cells is dependent upon the helicase cofactor Cdc45. Cell Death Differ 15: 889-898, 2008.

22. Rodriguez R and Meuth M: Chk1 and p21 cooperate to prevent apoptosis during DNA replication fork stress. Mol Biol Cell 17: 402-412, 2006

23. Meuth M: Chk1 suppressed cell death. Cell Div 5: 21, 2010.

24. Qatsha KA, Rudolph C, Marme D, Schachtele C and May WS: Go 6976, a selective inhibitor of protein kinase C, is a potent antagonist of human immunodeficiency virus 1 induction from latent/low-level-producing reservoir cells in vitro. Proc Natl Acad Sci USA 90: 4674-4678, 1993.

25. Shechter D, Costanzo V and Gautier J: Regulation of DNA replication by ATR: signaling in response to DNA intermediates. DNA Repair (Amst) 3: 901-908, 2004.
26. Gagou ME, Zuazua-Villar P and Meuth M: Enhanced H2AX phosphorylation, DNA replication fork arrest, and cell death in the absence of Chk1. Mol Biol Cell 21: 739-752, 2010.

27. Fujikane T, Shimizu T, Tsuji T, Ishida S, Ohsaki Y and Onodera S: Flow cytometric analysis of the kinetic effects of cisplatin on lung cancer cells. Cytometry 10: 788-789, 1989.

28. Smith ML: Mdm2 sensitizes MCF7 breast cancer cells to cisplatin or carboplatin. Breast Cancer Res Treat 58: 99-105, 1999.

29. Pabla N, Huang S, Mi QS, Daniel R and Dong Z: ATR-Chk2 signaling in 553 activation and DNA damage response during cisplatin-induced apoptosis. J Biol Chem 283: 6572-6583, 2008.

30. Lee SI, Brown MK and Eastman A: Comparison of the efficacy of 7-hydroxystaurosporine (UCN-01) and other staurosporine analogs to abrogate cisplatin-induced cell cycle arrest in human breast cancer cell lines. Biochem Pharmacol 58: 1713-1721, 1999.

31. Sato S, Fujita N and Tsuruo T: Interference with PDK1-Akt survival signaling pathway by UCN-01 (7-hydroxystaurosporine). Oncogene 21: 1727-1738, 2002.

32. Martiny-Baron G, Kazanietz MG, Mischak H, et al: Selective inhibition of protein kinase $\mathrm{C}$ isozymes by the indolocarbazole Go 6976. J Biol Chem 268: 9194-9197, 1993.

33. Eastman A, Kohn EA, Brown MK, et al: A novel indolocarbazole, ICP-1, abrogates DNA damage-induced cell cycle arrest and enhances cytotoxicity: similarities and differences to the cell cycle checkpoint abrogator UCN-01. Mol Cancer Ther 1: 1067-1078, 2002.

34. Bunch RT and Eastman A: Enhancement of cisplatin-induced cytotoxicity by 7-hydroxystaurosporine (UCN-01), a new G2-checkpoint inhibitor. Clin Cancer Res 2: 791-797, 1996.

35. Graves PR, Yu L, Schwarz JK, et al: The Chk1 protein kinase and the $\mathrm{Cdc} 25 \mathrm{C}$ regulatory pathways are targets of the anticancer agent UCN-01. J Biol Chem 275: 5600-5605, 2000.

36. Behrens MM, Strasser U and Choi DW: Go 6976 is a potent inhibitor of neurotrophin-receptor intrinsic tyrosine kinase. J Neurochem 72: 919-924, 1999.

37. Grandage VL, Everington T, Linch DC and Khwaja A: Go6976 is a potent inhibitor of the JAK 2 and FLT3 tyrosine kinases with significant activity in primary acute myeloid leukaemia cells. $\mathrm{Br}$ J Haematol 135: 303-316, 2006.

38. Sidi S, Sanda T, Kennedy RD, et al: Chk1 suppresses a caspase-2 apoptotic response to DNA damage that bypasses $\mathrm{p} 53, \mathrm{Bcl}-2$, and caspase-3. Cell 133: 864-877, 2008.

39. Myers K, Gagou ME,Zuazua-Villar P, Rodriguez R and Meuth M: ATR and Chk1 suppress a caspase-3-dependent apoptotic response following DNA replication stress. PLoS Genet 5: e1000324, 2009.

40. O'Connell MJ, Raleigh JM, Verkade HM and Nurse P: Chk1 is a weel kinase in the G2 DNA damage checkpoint inhibiting cdc2 by Y15 phosphorylation. EMBO J 16: 545-554, 1997.

41. Centurion SA, Kuo HR and Lambert WC: Damage-resistant DNA synthesis in Fanconi anemia cells treated with a DNA cross-linking agent. Exp Cell Res 260: 216-221, 2000.

42. Pichierri P and Rosselli F: The DNA crosslink-induced S-phase checkpoint depends on ATR-CHK1 and ATR-NBS1-FANCD2 pathways. EMBO J 23: 1178-1187, 2004.

43. Janetka JW and Ashwell S: Checkpoint kinase inhibitors: a review of the patent literature. Expert Opin Ther Pat 19: 165-197, 2009. 